\title{
Pulmonary emphysema and atherosclerosis: association or syndrome?
}

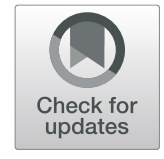

\author{
Atef W. Elrefai ${ }^{1}$, Mohammad Mossaad Alsayyad ${ }^{2}$ and Elsayed Mohamed Abd El-Hamid Hassan Dawood ${ }^{3^{*}}$
}

\begin{abstract}
Background: Atherosclerosis is an inflammatory reaction of the vessel wall. Emphysema may induce systemic inflammation, part of which may be the development or progression of atherosclerosis. So, the relationship between emphysema and atherosclerosis, whether both are due to the same causative agent and pathogenesis or emphysema led to atherosclerosis, is still not clearly understood. So, the aim of this work is to study the relationship between carotid atherosclerosis versus pulmonary emphysema extent and aifflow obstruction.

Results: Cigarette smoking index was higher in patients than controls. According to FEV1\%, patients were classified into: GOLD 1 (mild): FEV1 $\geq 80 \%$ predicted, GOLD 2 (moderate): 50\% $\leq$ FEV1 < 80\% predicted, GOLD 3 (severe):30\% $\leq$ FEV1 < 50\% predicted, and GOLD 4 (very severe): FEV1 < 30\% predicted. There was a significant difference between the studied groups as regard to ABG parameters. Emphysema score showed a positive correlation with thrombus size, plaque size, and stenosis percent. Approximately $2 / 3$ of patients had atherosclerotic changes and the other 1/3 had increased IMT. GOLD staging, also, correlated with thrombus size and stenosis percent. So, there was a strong positive correlation between both emphysema score and GOLD staging and carotid atherosclerosis.

Conclusion: The relationship between emphysema and atherosclerosis is suggested to be the chronic inflammatory reaction (against the same risk factor) based on the positive correlation between carotid atherosclerosis versus emphysema score and GOLD staging. The inherence of emphysema and atherosclerosis may be considered a syndrome. If so, targeting the same pathogenic mechanism will be valuable for their control.
\end{abstract}

Keywords: Pulmonary emphysema, Emphysema, Carotid atherosclerosis

\section{Background}

Emphysema is a chronic inflammatory response due to cigarette smoke and other noxious particles with subsequent progressive airflow limitation ending in gas trapping [1]. On one side, COPD in most patients is associated with chronic diseases that share with the COPD the same risk factors like smoking, aging, and inactivity; these chronic diseases affect the morbidity and mortality of COPD [2]. COPD as a chronic

\footnotetext{
*Correspondence: sayeddawood71@yahoo.com

${ }^{3}$ Radiology Department, Al-Azhar University, Faculty of Medicine, New Damietta, Egypt

Full list of author information is available at the end of the article
}

inflammatory disease and through inflammatory mediators in the circulation may lead to the development or deterioration of other comorbidities like ischemic heart disease, metabolic syndrome, etc. [1].

The pathogenesis of the pulmonary emphysema had been suggested to be due to the increased elastolytic activity of neutrophil proteinases [3], oxidative stress that increases with cell senescence [4], the cellular and molecular factors, alveolar cell apoptosis, autoimmune, and genetic factors [5]. In addition, matrix metalloproteinases unbalance with their tissue inhibitors was suggested to contribute to the cerebrovascular damage in COPD [6]. Also, the systemic inflammation and endothelial dysfunction, according

\section{Springer Open}

(c) The Author(s). 2020 Open Access This article is licensed under a Creative Commons Attribution 4.0 International License, which permits use, sharing, adaptation, distribution and reproduction in any medium or format, as long as you give appropriate credit to the original author(s) and the source, provide a link to the Creative Commons licence, and indicate if changes were made. The images or other third party material in this article are included in the article's Creative Commons licence, unless indicated otherwise in a credit line to the material. If material is not included in the article's Creative Commons licence and your intended use is not permitted by statutory regulation or exceeds the permitted use, you will need to obtain permission directly from the copyright holder. To view a copy of this licence, visit http://creativecommons.org/licenses/by/4.0/. 
Table 1 Patient characteristics of studied populations

\begin{tabular}{|c|c|c|c|c|}
\hline \multicolumn{2}{|c|}{ Variables } & \multirow{2}{*}{$\frac{\text { COPD }}{64.2 \pm 5.6}$} & \multirow{2}{*}{$\begin{array}{l}\text { Control } \\
64.37 \pm 5.1\end{array}$} & \multirow{2}{*}{$\frac{p \text { value }}{0.86 \text { (ns) }}$} \\
\hline Age & & & & \\
\hline \multirow[t]{2}{*}{ Sex } & Male & 68(85.0\%) & $27(67.5 \%)$ & 0.26 (ns) \\
\hline & Female & $12(15.0 \%)$ & $13(32.5 \%)$ & \\
\hline \multicolumn{2}{|c|}{ Packs/year } & $24.35 \pm 14.64$ & $14.75 \pm 15.13$ & $0.001^{*}$ \\
\hline
\end{tabular}

*Denoting the value is significant

to several studies, are incriminated in the development of the pulmonary and extrapulmonary vascular changes in COPD [7-15].

This systemic inflammation with endothelial dysfunction, also, promote the systemic vascular alteration in atherosclerosis [15-19], elevating the suggestion of the relation between atherosclerosis and COPD as regards to the same pathogenesis, particularly after the conclusion of many studies that atherosclerosis is predominantly an inflammatory reaction of the vessel wall [20].

The risk stratification of cardiovascular morbidity and mortality in COPD lacks established biomarkers, besides the normal lipid profile in most patients [21]. Hence, using common carotid artery ultrasonography being able to measure intima-media thickness (IMT) and to detect early atherosclerotic lesions, is a useful tool for risk-stratification [22, 23]. The carotid intima-media thickness (CIMT) measurement by ultrasonography is not only an indicator of atherosclerosis but also an indicator of cardiovascular (CV) events and mortality [24-27]. Besides that, there is a correlation between CIMT increase and airflow obstruction severity in COPD [28-30]. Explanation of the increase of CIMT in COPD is claimed to be due to systemic inflammation, endothelial dysfunction, hypoxia [30], a sedentary lifestyle, high smoking prevalence [31], hypercoagulability, platelet activation, and oxidative stress [32-34] rather than lipid-driven atherosclerosis [35]. Moreover, elastin degradation in the extracellular matrix of the arterial wall results in emphysema in the lungs and atherosclerosis in the vasculature $[34,36]$.

So, if both conditions (emphysema and atherosclerosis) have the same pathogenesis, the different stages of both could coincide. If this is proved, the relationship between them may be considered inherent more than just association.

\section{Purpose}

To study the relationship between carotid atherosclerosis and pulmonary emphysema extent and airflow obstruction.

\section{Methods}

\subsection{Study design}

This study was conducted on 80 patients with emphysema and 40 controls, conducted at the Chest Department, in the period from November 2016 to November 2017. The diagnosis of COPD was based on GOLD criteria [1]. All included subjects were submitted to the following: (1) full history taking: with special attention to the main complaint, age, sex, smoking status, duration of disease, risk factors (occupation, pollution, resident area, diabetes mellitus, dyslipidemia, etc.); (2) clinical examination; (3) HRCT of the chest reported by two observers; (4) ABG: PH, partial arterial oxygen tension $(\mathrm{PaO} 2)$, partial arterial carbon dioxide tension $(\mathrm{PaCO} 2)$, and arterial oxygen saturation $(\mathrm{SaO} 2)$ were measured in the arterial blood sample at room air after $20 \mathrm{~min}$ from performing the HRCT; (5) spirometric tests: all subjects underwent spirometry with

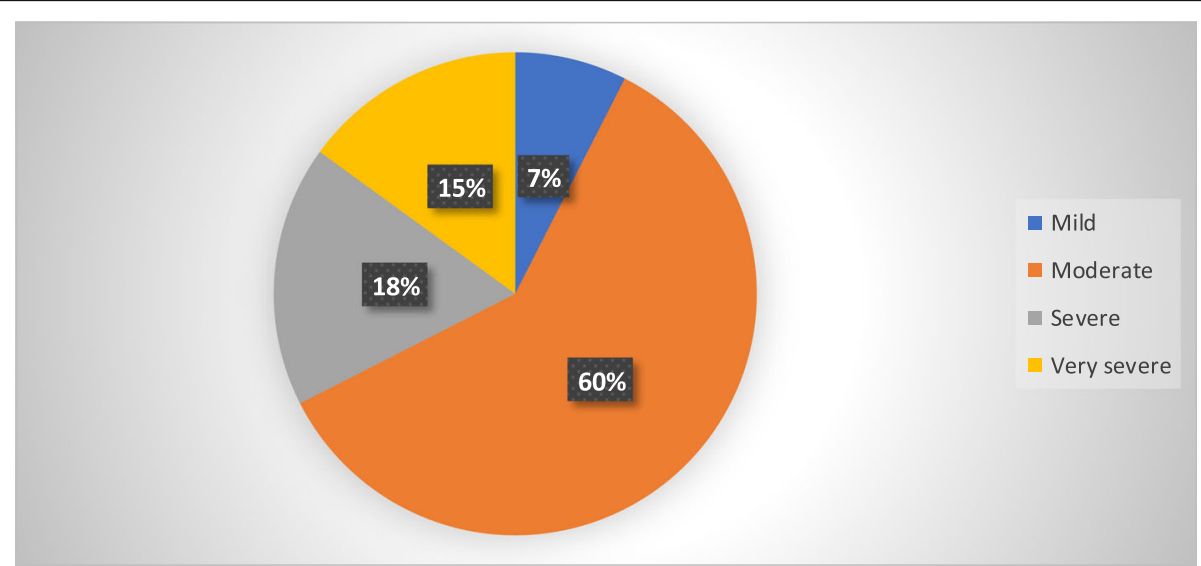

Fig. 1 GOLD classification 
Table 2 Correlation between emphysema score and carotid duplex

\begin{tabular}{lll}
\hline Carotid duplex & \multicolumn{2}{l}{ Emphysema score } \\
\cline { 2 - 3 } & $\boldsymbol{R}$ & $\boldsymbol{P}$ \\
\hline Right thrombus size & $.839^{* *}$ & .000 \\
Right plaque size & $.870^{* *}$ & .000 \\
Right stenosis percent & $.878^{* *}$ & .000 \\
Left thrombus size & $.861^{* *}$ & .000 \\
Left plaque size & $.305^{* *}$ & .006 \\
left stenosis percent & $.938^{* *}$ & .000 \\
\hline
\end{tabular}

*Denoting the value is significant

special measurement of; forced vital capacity (FVC), forced expiratory volume in 1 second\% predicted (FEV1\%), and FEV1/FVC ratio; (6) carotid duplex; control group consisted of age and sex-matched volunteers with no history of chronic chest diseases; in addition, lipid profile, fasting and postprandial BS, liver, kidney functions were done.

\subsection{Exclusion criteria}

The presence of systemic hypertension, diabetes mellitus, known cardio/cerebrovascular diseases, dyslipidemia, or history of lipid-lowering drug intake excluded the subject from the study.

\section{Study protocol}

A. Spirometry studies: were performed via ZAN MEBGERAEE GMBH D-97223 Oberthulba, Schlimpfhoferstr, Messgeraete GmbH Germany, Spirometry, according to the American Thoracic Society/European Respiratory Society standards [37]. According to GOLD, spirometry was required to diagnose emphysema and FEV1/FVC ratio $<0.70$ confirmed persistent airflow limitation presence. Then, the severity of airflow limitation was classified on basis of a postbronchodilator FEV 1[1].

B. Carotid Doppler U/S: was performed with a 7.5 MHZ superficial linear array transducer of (TOSHIBA, Xario 200, TOSHIBA Medical

Table 3 Lipid profile and blood sugar among studied groups

\begin{tabular}{llll}
\hline Variables & COPD & Control & $\boldsymbol{p}$ value \\
\hline Cholesterol & $164.00 \pm 22.23$ & $160.90 \pm 24.24$ & 0.48 (ns) \\
TG & $81.23 \pm 17.46$ & $84.55 \pm 15.56$ & 0.31 (ns) \\
Fasting BS & $104.06 \pm 4.07$ & $104.97 \pm 7.38$ & 0.38 (ns) \\
Postprandial BS & $132.22 \pm 4.59$ & $128.15 \pm 19.28$ & 0.08 (ns) \\
\hline
\end{tabular}

Table 4 Intraclass absolute agreement between two observers for emphysema score

\begin{tabular}{lllll}
\hline & $\begin{array}{l}\text { Intraclass } \\
\text { correlation } \\
\text { coefficient } \\
\text { (ICC) }\end{array}$ & $\begin{array}{l}\text { 95\% Confidence } \\
\text { interval(Cl) }\end{array}$ & p value \\
\cline { 3 - 4 } & $\begin{array}{l}\text { Lower } \\
\text { bound }\end{array}$ & $\begin{array}{l}\text { Upper } \\
\text { bound }\end{array}$ & \\
\hline Single measures & $.997 \mathrm{~b}$ & .996 & .998 & $<0.001^{*}$ \\
$\begin{array}{l}\text { Average } \\
\text { MEASURES }\end{array}$ & $.999 \mathrm{C}$ & .998 & .999 & $<0.001^{*}$ \\
\hline *Denoting the value is significant & & & & \\
\hline
\end{tabular}

System, Japan) in axial and longitudinal section in B mode, by a single experienced operator. The images obtained during the ultrasonographic imaging were recorded electronically and then evaluated. The patient was lying in a supine position, lifting his neck at an angle of approximately $20^{\circ}$ to the front. The far walls of the right and left common carotid arteries were evaluated. The intima-media thickness was defined as the distance between the leading edge of the lumen intima echo and the leading edge of the media-adventitia echo. The averages of the CIMT values obtained from the far walls of the right and left common carotid arteries were calculated. Measurements were taken at least $10 \mathrm{~mm}$

Table 5 Atherosclerotic plaques in studied groups

\begin{tabular}{|c|c|c|c|c|c|c|}
\hline & & \multicolumn{2}{|c|}{ COPD } & \multicolumn{2}{|c|}{ Control } & \multirow{2}{*}{$\begin{array}{l}p \\
\text { value }\end{array}$} \\
\hline & & $\bar{n}$ & $\%$ & $N$ & $\%$ & \\
\hline \multirow[t]{4}{*}{ Right surface } & No plaque & 25 & $31.3 \%$ & 40 & $100.0 \%$ & $<0.001^{*}$ \\
\hline & Smooth & 16 & $20.0 \%$ & 0 & $.0 \%$ & \\
\hline & Irregular & 31 & $38.8 \%$ & 0 & $.0 \%$ & \\
\hline & Ulcer & 8 & $10.0 \%$ & 0 & $.0 \%$ & \\
\hline \multirow[t]{3}{*}{ Right hemogoniecity } & No plaque & 25 & $31.3 \%$ & 40 & $100.0 \%$ & $<0.001^{*}$ \\
\hline & Homogeneous & 23 & $28.8 \%$ & 0 & $.0 \%$ & \\
\hline & Heterogeneous & 32 & $40.0 \%$ & 0 & $.0 \%$ & \\
\hline \multirow[t]{3}{*}{ Right calcification } & No plaque & 25 & $31.3 \%$ & 40 & $100.0 \%$ & $<0.001^{*}$ \\
\hline & Soft & 13 & $16.3 \%$ & 0 & $.0 \%$ & \\
\hline & Calcified & 42 & $52.5 \%$ & 0 & $.0 \%$ & \\
\hline \multirow[t]{4}{*}{ Left surface } & No plaque & 23 & $28.8 \%$ & 40 & $100.0 \%$ & $<0.001^{*}$ \\
\hline & Smooth & 18 & $22.5 \%$ & 0 & $.0 \%$ & \\
\hline & Irregular & 31 & $38.8 \%$ & 0 & $.0 \%$ & \\
\hline & Ulcer & 8 & $10.0 \%$ & 0 & $.0 \%$ & \\
\hline \multirow[t]{3}{*}{ Left hemogoniecity } & NO plaque & 23 & $28.8 \%$ & 40 & $100.0 \%$ & $<0.001^{*}$ \\
\hline & Homogeneous & 16 & $20.0 \%$ & 0 & $.0 \%$ & \\
\hline & Heterogeneous & 41 & $51.3 \%$ & 0 & $.0 \%$ & \\
\hline \multirow[t]{3}{*}{ Left calcification } & No plaque & 23 & $28.8 \%$ & 40 & $100.0 \%$ & $<0.001^{*}$ \\
\hline & Soft & 15 & $18.8 \%$ & 0 & $.0 \%$ & \\
\hline & Calcified & 42 & $52.5 \%$ & 0 & $.0 \%$ & \\
\hline
\end{tabular}

*Denoting the value is significant 
proximal to the carotid bifurcation, in the near and far wall of the left and right common carotid arteries. Repeated measurements were performed along with a minimum of $10 \mathrm{~mm}$ length. Four measurements were taken from both the left and right common carotid arteries (two in the near and two in the far wall). The maximal measurement from these eight measurements was used for analysis, according to the 'Mannheim Carotid Intima-Media Thickness Consensus' [38]. A thickening $\geq 1.5 \mathrm{~mm}$ was categorized as an atheromatous plaque [39].

C. HRCT: examination was carried out with (TOSHIBA, Aquilion prime, 80 dual MDCT system, Japan) Examination was performed with the subject in the supine position at the end-inspiratory state. A total of $0.5-\mathrm{mm}$ thick slices at $10-\mathrm{mm}$ intervals $(120 \mathrm{kVp}, 250 \mathrm{~mA}, 1$-s scanning time) were obtained from the diaphragm to the lung apex. A highfrequency reconstruction algorithm was used. Images format with window setting 1200/a500 Hounsfield units.
D. Visual analysis: radiologist and pulmonologist blindly and independently evaluated CT slices of subjects using the extent of emphysema. The evaluation was performed slice-by-slice, both lung fields together, and results were later combined as the total scores of each subject [40]. Emphysema was defined as hypovascular areas of pulmonary parenchyma not associated with a fissure, usually lacking a well-defined wall. Changes were decreased attenuation, few or no vessels, and bullae with a well- or ill-defined wall. The scale used was: $0=$ normal; $1=$ emphysema in $25 \%$ of the slice; $2=$ emphysema in $25-50 \%$ of the slice; $3=$ emphysema in $50-75 \%$ of the slice; and $4=$ emphysema in $>75 \%$ of the slice; as the maximum score in each slice was 4 and 10 slices were imaged per patient, the maximum possible score was 40 [41].

\section{Statistical methodology}

Data entry and analysis were done using SPSS version 17, data were presented as mean, SD, Median, No., and percentage, Cochran Armitage chi-square test was used to compare qualitative data between the two groups of patients, independent samples $T$ test was

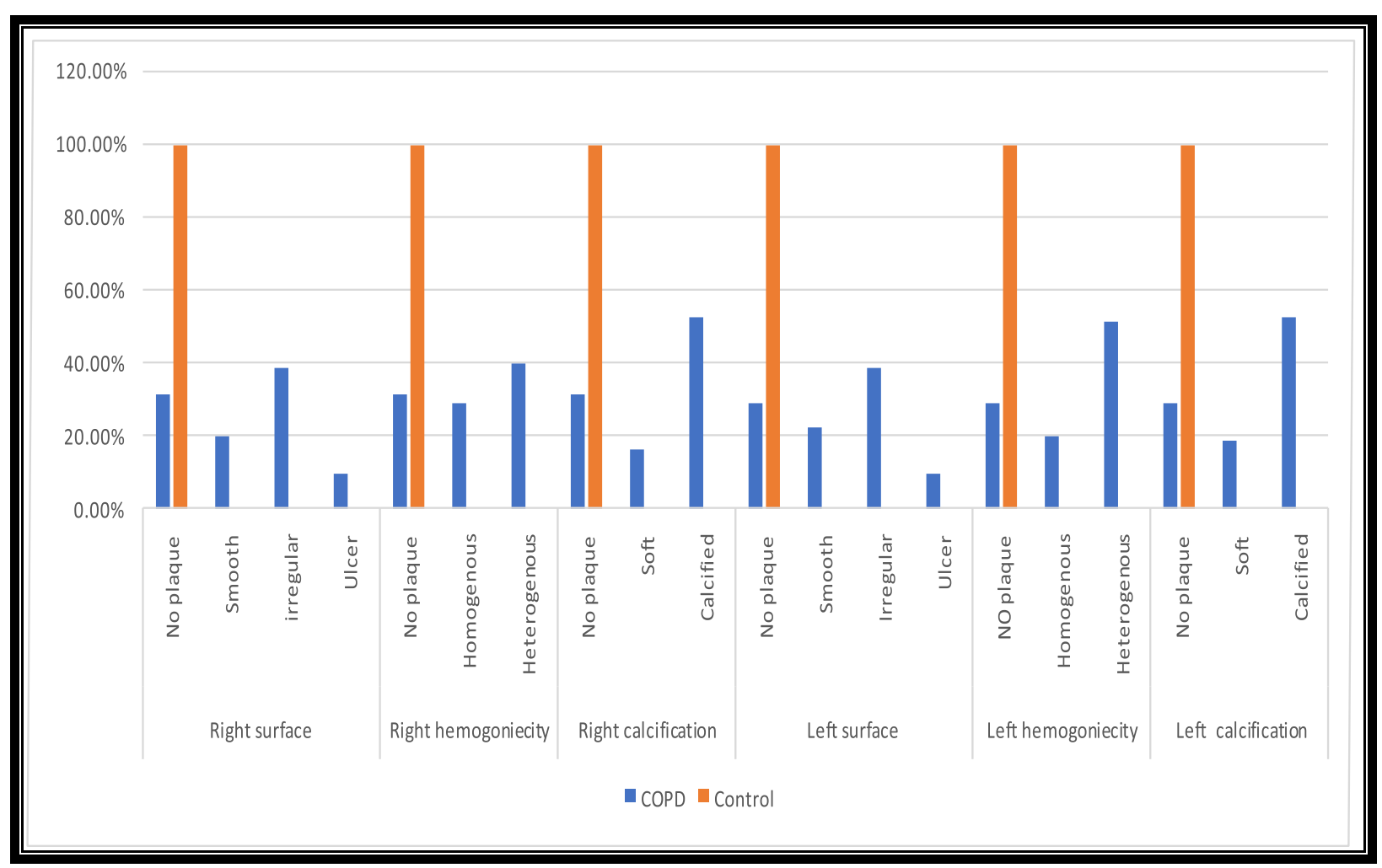

Fig. 2 Atherosclerotic plaques in studied groups 


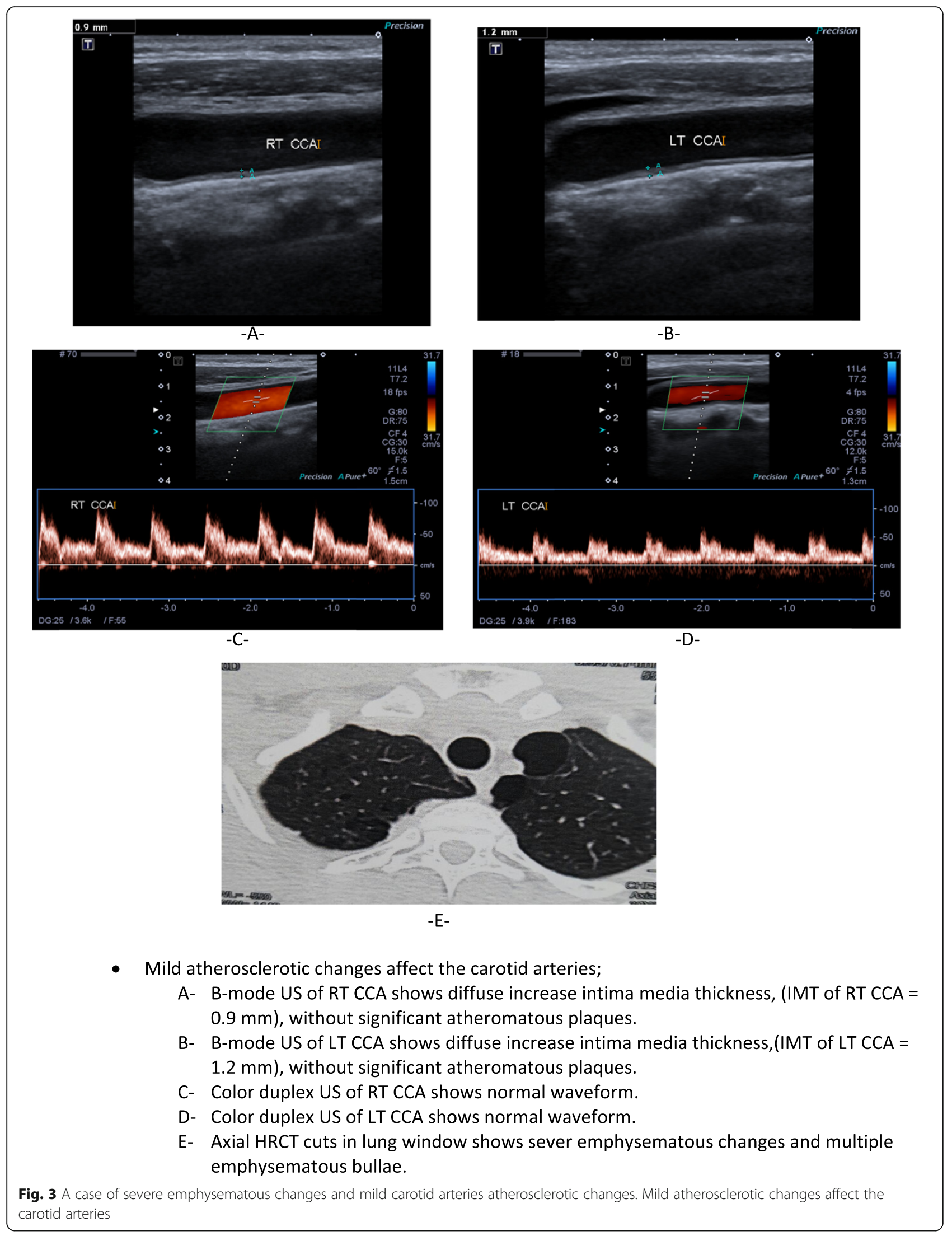


used to compare means of both groups, paired samples $T$ test was used to compare means before and after the procedure (CA or $\mathrm{PCI}$ ) in the same group. $P$ value is considered significant when it is $<0.05$; Regression analysis was done and or was calculated for independent risk factors, all results were presented in the form of tables and figures.

\section{Results}

In the present study, there was no significant difference between studied groups as regards to patient age and sex. However, there was a statistically significant difference between studied groups as regards to cigarette smoking index (Table 1).

Patients were classified into GOLD 1 (mild): FEV1 $\geq$ $80 \%$ predicted $(n .=6[7.5 \%]) /$ GOLD 2 (moderate): $50 \%$ $\leq$ FEV $1<80 \%$ predicted $(n .=48[60 \%]) /$ GOLD $3($ severe): $30 \% \leq \mathrm{FEV} 1<50 \%$ predicted $(n .=14[17.5 \%])$ /GOLD 4 (very severe): FEV1 < 30\% predicted $(n .=12$ [15\%]). There was a statistically significant difference between studied groups as regards to $\mathrm{SaO} 2, \mathrm{PH}, \mathrm{PaO} 2$, and PaCO2 (Fig. 1) (Table 2).

There was a statistically significant difference between studied groups as regard to FEV1\%, FEV1/FVC, $\mathrm{SaO} 2, \mathrm{PH}, \mathrm{PaO} 2$, and $\mathrm{PaCO} 2$ (Table 3). However, there was no significant difference between studied groups as regard to cholesterol, TG, fasting, and postprandial BS (Table 4).

In our work, the Intraclass Correlation Coefficient (ICC) for absolute agreement between two observers showed a high statistically significant absolute agreement between two observers in the reading of the emphysema score. Our estimated ICC was 0.999 , with a $95 \%$ confidence interval $(\mathrm{CI})(0.998,0.999)$, and this was considered excellent.

In the present work, there was a highly positive correlation between emphysema score from one side and each of thrombus size $(r=.839$ on the right side and $r=.861$ on the left), plaque size ( $r=.870$ right and $r=.305$ left) and stenosis percent ( $r=.878$ right and $r=.938$ left) on both sides (Table 2).

In the studied groups, there was a statistically significant difference between COPD patients and controls as regards to atherosclerotic changes in the right and left carotid U/S findings. The incidence of carotid atherosclerotic plaques reached $68.8 \%$ on the right side and $71.3 \%$ on the left side, over that, the rest of patients without plaques showed an increase in IMT. The plaques were with smooth surface in $20 \%$, irregular surface in $38.8 \%$, ulcer in $10 \%$, and homogeneous in $28.8 \%$, heterogeneous in $40 \%$, soft in $16.3 \%$ and calcific in $52.5 \%$ on the right side, and with smooth surface in $22.5 \%$, irregular surface in $38.8 \%$, ulcer in $10 \%$, and homogeneous in $20 \%$, heterogeneous in
$51.3 \%$, soft in $18.8 \%$, and calcific in $52.5 \%$ on the left side (Table 5), (Fig. 2).

There were positive correlations between GOLD staging from one side and each of right thrombus size $(r=$ .423), right plaque size $(r=.451)$, right stenosis percent $(r=.516)$, and left thrombus size $(r=.440)$.

\section{Discussion}

In our work, the ICC for absolute agreement between two observers in reading emphysema score in chest HRCT showed high statistical significance $(0.999, p<$ $0.001)$.

The use of B-mode ultrasound and carotid duplex can identify and quantify atherosclerosis and predict the risk for cardiovascular disease (CVD) and stroke in COPD patients [42].

Our study revealed a high incidence of carotid atherosclerotic plaques among about $70 \%$ of emphysema patients $(68.8 \%$ on the right and $71.3 \%$ on the left side), while the rest of patients showed an increase in the IMT as an indicator of subclinical atherosclerosis. In addition, carotid atherosclerosis correlated well with emphysema CT score and more than its correlation with GOLD staging. This denotes the intimate association between atherosclerosis and emphysema with the slight prevalence of atherosclerotic changes in the left side. Of note that, cholesterol and TG levels in these patients were in the normal range.

In agreement with our study, Hafez et al. [34] found atherosclerosis prevalence in COPD patients reaching about 64\% (approximately two-thirds of COPD patients had atherosclerosis). Also, in agreement with the present study, the emphysema extent and airflow obstruction had been reported to correlate with atherosclerosis [7-11, 43].

FEV1 is considered a clinical indicator commonly used to evaluate the COPD severity [44], and GOLD classification of COPD depends mainly on FEV1. Our study showed a positive correlation between GOLD staging and carotid atherosclerosis.

Barr et al. [35] reported the decrease in FEV1 to be an independent risk factor for carotid atherosclerosis and emphysema. Similarly, Alpaydin et al. [45], after adjusting their study for smoking, TG and cholesterol levels, hypertension, and fasting plasma glucose, had found IMT to be higher in COPD versus controls, and they suggested other mechanisms than smoking to be responsible for the association between COPD and IMT. So, airflow limitation and hypoxia are suggested to be responsible for the association between emphysema and carotid atherosclerosis. In a study by van Gestel et al., [23] they found moderate to severe COPD, independently and irrespective of associating comorbidities and smoking status, to be associated 

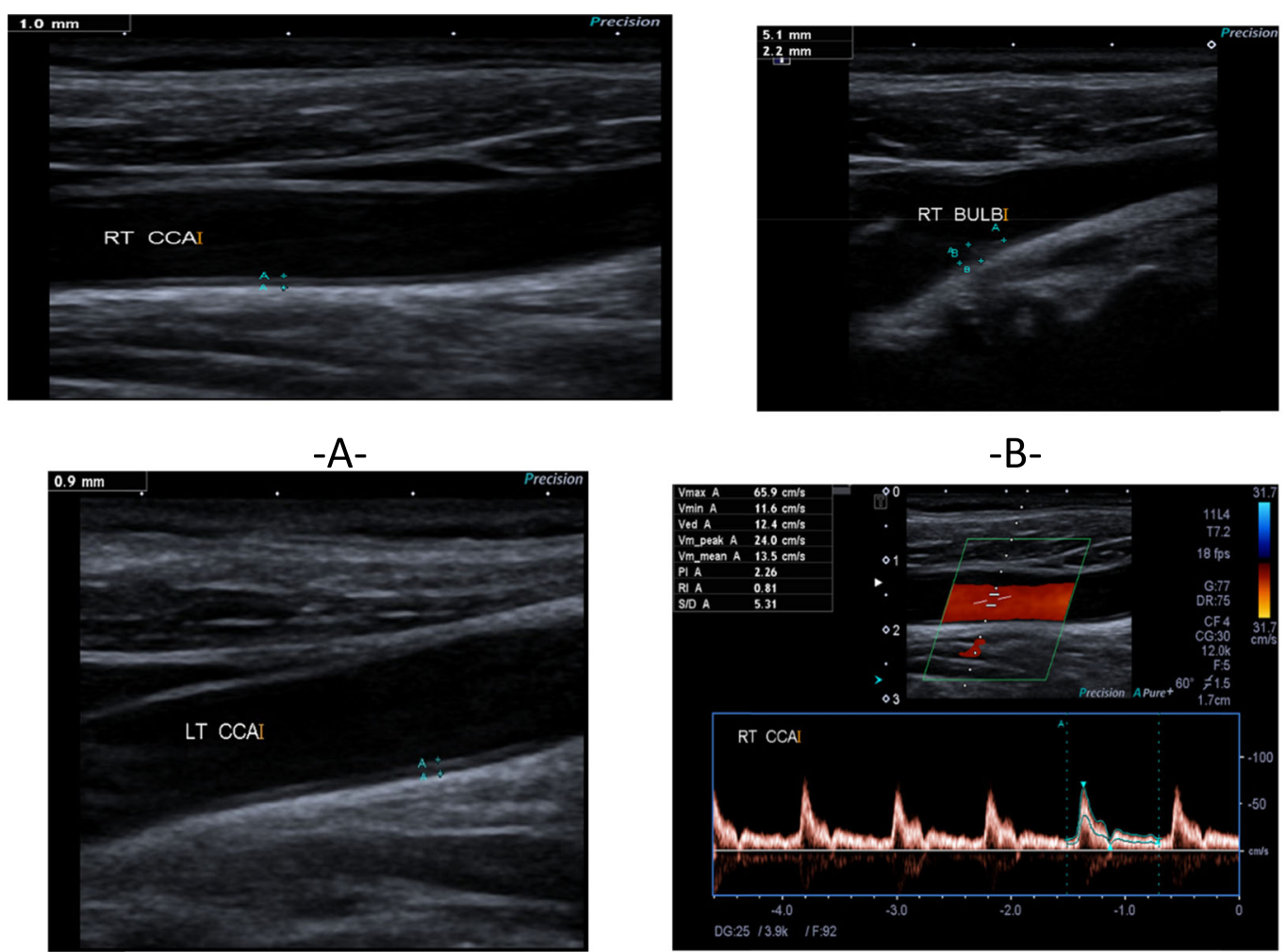

$-\mathrm{C}-$

$-D-$

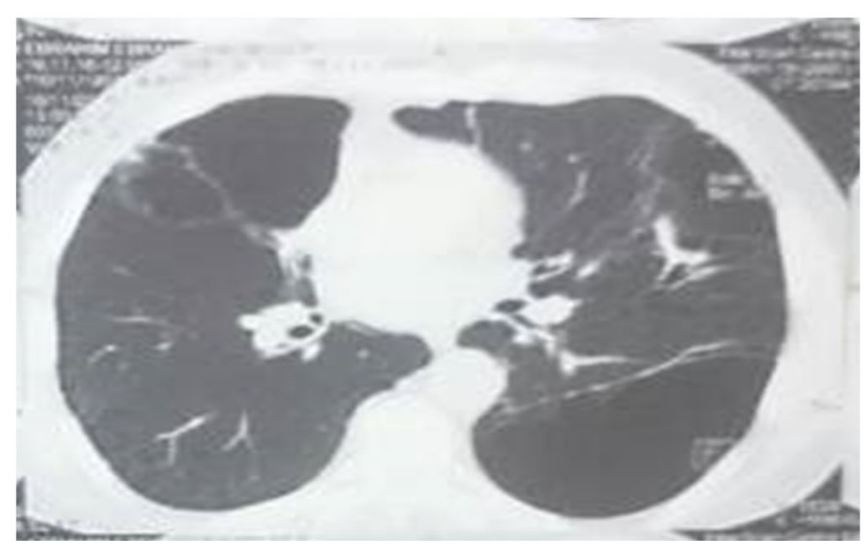

$-\mathrm{E}-$

- Mild atherosclerotic changes affect the carotid arteries;

A- B-mode US of RT CCA shows diffuse increase intima media thickness, (IMT of RT CCA $=1 \mathrm{~mm}$ ).

B- B-mode US of RT CCA shows Soft non calcified atheromatous plaque is noted involve the bulb of RT CCA measure about $5.1 \times 2.2 \mathrm{~mm}$.

C- B-mode US of LT CCA shows diffuse increase intima media thickness,(IMT of LT CCA $=0.9 \mathrm{~mm}$ ), without significant atheromatous plaques.

D- Color duplex US of RT CCA shows normal waveform.

E- Axial HRCT cuts in lung window shows sever emphysematous changes and multiple emphysematous bullae

Fig. 4 A case of severe emphysematous changes and mild carotid arteries atherosclerotic changes 


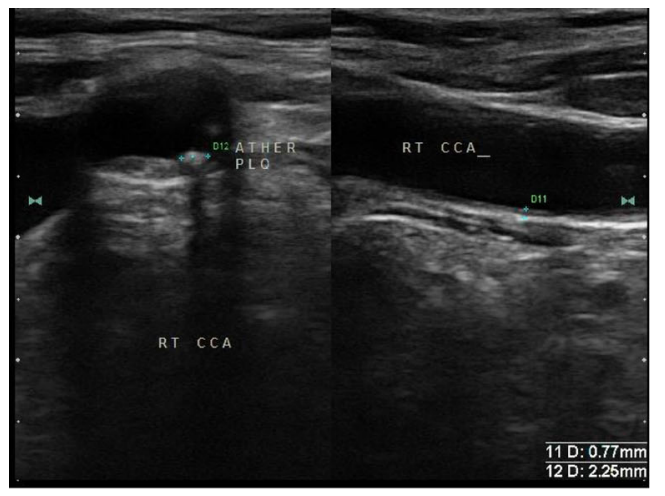

$-A-$

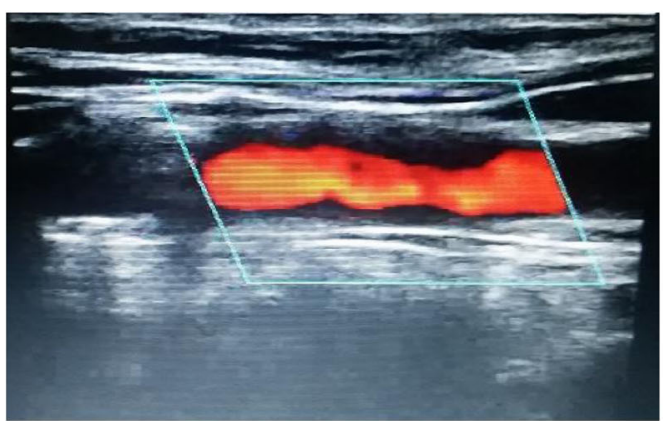

$-\mathrm{C}-$

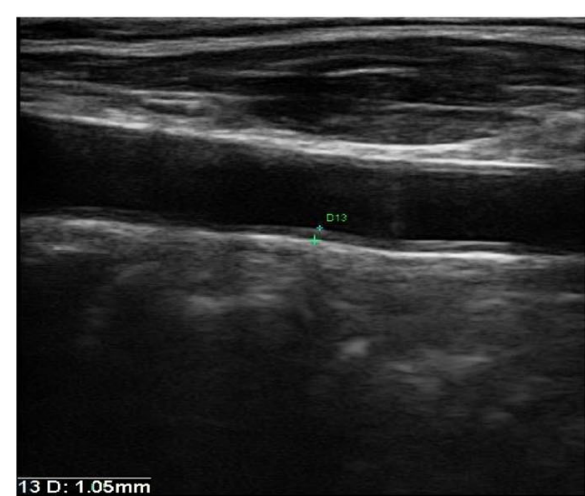

-B-

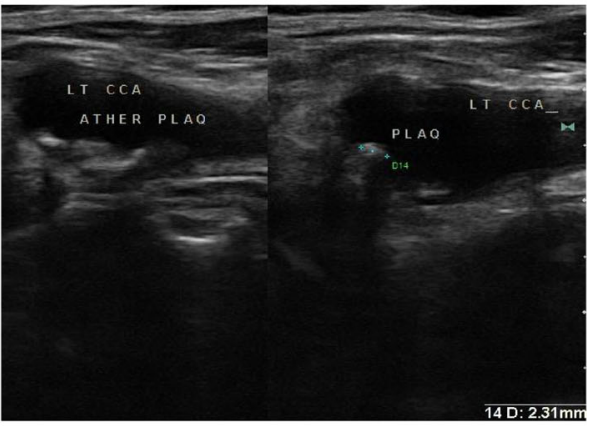

-D-

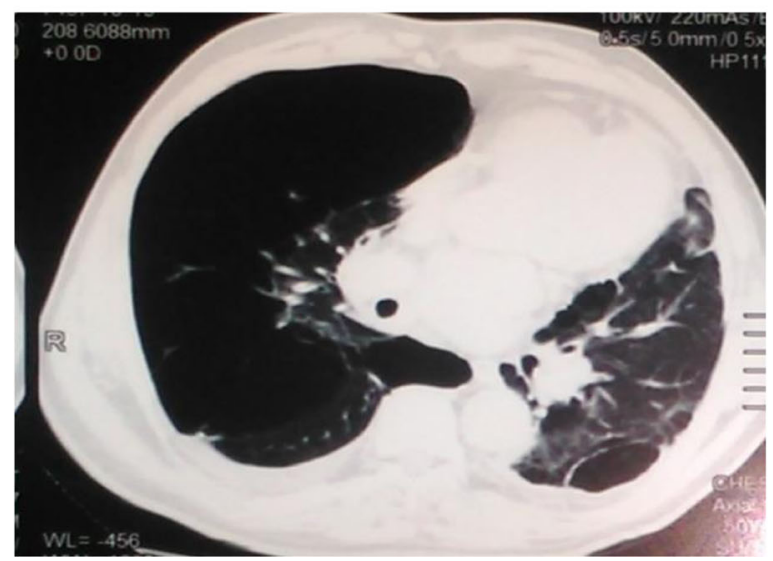

$-E-$

- Moderate atherosclerotic changes affect the carotid arteries;

A- B-mode US of RT CCA shows diffuse increase intima media thickness, (IMT of RT CCA = $0.8 \mathrm{~mm}$ ), with soft \& calcified atheromatous plaques are noted involve RT carotid bulb.

B- B-mode US of LT CCA shows diffuse increase intima media thickness,(IMT of LT CCA $=1 \mathrm{~mm}$ ).

C- B-mode US of LT CCA shows calcified atheromatous plaques are noted through the LT carotid bulb, the largest is noted at the LT carotid bulb measure about $2.3 \mathrm{~mm}$.

D- Colourdoppler US shows irregular outline of the common carotid artery secondary to atherosclerotic changes.

E- Axial HRCT cuts in lung window shows sever emphysematous changes and multiple emphysematous bullae

Fig. 5 A case of severe emphysematous changes and moderate carotid arteries atherosclerotic changes 


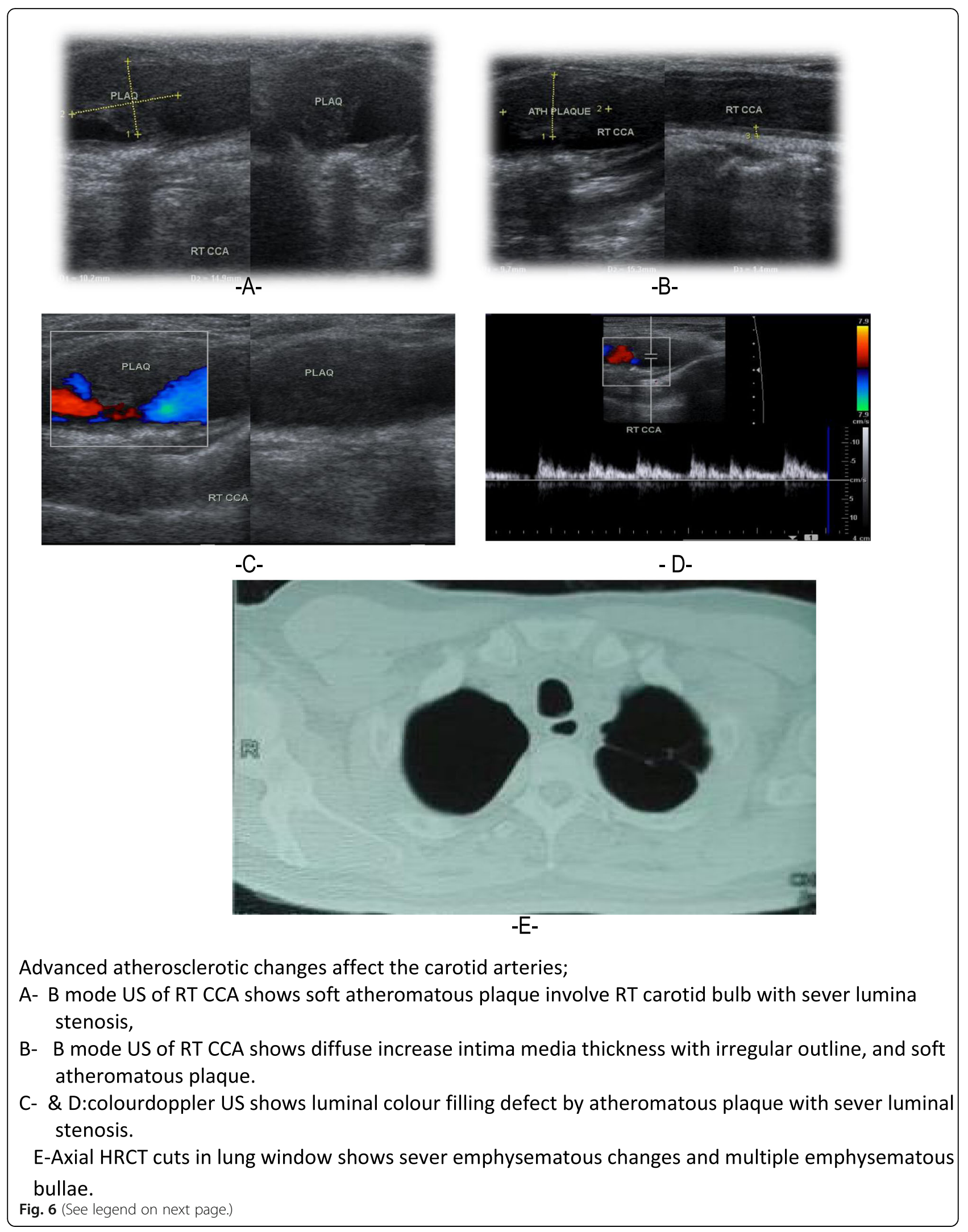


(See figure on previous page.)

Fig. 6 A case of severe emphysematous changes and advanced carotid arteries atherosclerotic changes. Advanced atherosclerotic changes affect the carotid arteries; a B mode US of RT CCA shows soft atheromatous plaque involve RT carotid bulb with sever lumina stenosis, $\mathbf{b}$ B mode US of RT CCA shows diffuse increase intima-media thickness with an irregular outline, and soft atheromatous plaque. $\mathbf{c}$ and $\mathbf{d}$ : colour doppler US shows luminal colour filling defect by an atheromatous plaque with severe luminal stenosis. e Axial HRCT cuts in the lung window show severe emphysematous changes and multiple emphysematous bullae

with increased IMT of the common carotid artery. In addition, Kim et al. [46] noticed IMT to be significantly correlated with FEV1, FEV1/FVC, and FVC, and suggested a bi-directional effect of COPD on CVS and vice versa. In a study by Köseoğlu et al.,[47] CIMT $>1.25 \mathrm{~mm}$ was found to carry a 12 -fold increased risk in COPD to have CAD (Figs. 3, 4, 5, and 6).

Hypoxemia and/or hypercapnia were considered relevant factors for atherosclerosis by Hafez et al. [34], on the basis of the significant decrease of $\mathrm{PaO} 2$ and significant increase of $\mathrm{PaCO} 2$ in $\mathrm{COPD}$ patients with increased CIMT versus those showing a normal CIMT. Systemic inflammation, oxidative stress, increased foam cell production, induction of hemodynamic stress, and upregulation of cell adhesion molecules are the possible mechanisms through which hypoxemia could lead to atherosclerosis [48-50].

In contrast to our study, Schroeder et al. [51] did not find an association between FEV1\% and carotid plaque. In addition, Matsuoka et al. [15] did not find FEV1 to be significantly correlated with the severity of aortic calcification, but they explained that by the difference in the evaluation techniques and the difference in the pathological processes involved in different stages of atherosclerosis. However, Iwamoto et al. [11] reported a significant correlation between FEV1\% and IMT. This may mean that airflow limitation initiates the increase in IMT, then the systemic inflammation induces atherosclerosis progression. Furthermore, atherosclerosis may be related to COPD phenotypes [15].

In a study by Pike et al .[52], they found that lung abnormalities may be directly related to carotid atherosclerosis in absence of airflow limitation in never- and ex-smokers. They suggested that subclinical airways disease may be present in never- and ex-smokers with increased IMT mediated by factors other than smoking. The relation of the extent of emphysema to arterial stiffness [8], and to endothelial dysfunction [7], besides the relation of endothelial dysfunction to systemic inflammation, both supported the conclusion of Matsuoka et al. [15] that emphysema and vascular alteration may be related by endothelial dysfunction and systemic inflammation.

Hypercholesterolemia is considered one of the main triggers of atherosclerosis [53]. So, the normal lipid profile in emphysema patients with atherosclerosis indicates the responsibility of other factors for this association. Atherosclerotic plaque in COPD patients has criteria that make them more easy to rupture [52], hence, the evaluation of carotid plaque composition/texture will be beneficial.

Our study results support the idea of complex heterogeneous lung and vascular disease in the context of an explanation of the relationship between emphysema and atherosclerosis, which also, was supported by other studies; Dransfield et al. [54], Chae et al. [55] showed the relationship between emphysema and each of carotid atherosclerosis, scores of calcification in the aorta, coronary arteries. Pike et al. [56] showed the significant relationship between upper-lobe emphysema and internal carotid IMT. In addition, [6] suggested the contribution of the imbalance of matrix metalloproteinases and their tissue inhibitors in the cerebrovascular damage in COPD $[34,36]$.

Emphysema \& Cancer Action Project study [7] incorporated thoracic CT for the evaluation of the brachial artery flow-mediated dilation in the ex-smokers group with early COPD and showed that reduced FEV1 and greater emphysema indices were associated with attenuation of flow-mediated dilatation giving the conclusion that both lung function and structure influence vascular endothelial function [56].

\section{Conclusion}

Atherosclerotic plaques were prevalent in about twothirds $(70 \%)$ of emphysema patients and the rest of the patient showed subclinical atherosclerosis. The positive correlation between the carotid atherosclerosis and emphysema CT score was more than with GOLD staging. So, this inherence between pulmonary emphysema and atherosclerosis may not be just an association, it may be a syndrome. Thus, the staging of each of them can be guided from the other, and therapies targeted against the same pathogenesis can benefit both conditions. So, we recommend that management plan for emphysema should include the carotid US for early detection and treatment of atherosclerosis.

Abbreviations

HRCT: High-resolution computed tomography; BS: Blood sugar; ABG: Arterial blood gas; GOLD: Global initiative for chronic Obstructive Lung Disease; 
COPD: Chronic obstructive pulmonary disease; CIMT: Carotid Intima-Media Thickness; CVD: Cardiovascular disease; PaO2: Partial arterial oxygen tension: $\mathrm{PaCO} 2$ : Partial arterial carbon dioxide tension; $\mathrm{SaO} 2:$ Arterial oxygen saturation; ICC: Intraclass correlation coefficient; Cl: Confidence interval; TG: Triglycerides; U/S: Ultrasonography; CAD: Coronary artery disease; FVC: Forced vital capacity

\section{Acknowledgement}

The authors thank all the study participants for their patience and support.

\section{Authors' contributions}

AW suggest idea of the work, planning \& design the work, clinical evaluation of the cases, observe HRCT studies, evaluation of pulmonary function tests, reviewing literature, Data collection and analysis, share in statistical analysis, write and revise the manuscript, share in preparation of the tables, share in preparation of the figures. MM discus the idea of the work, planning \& design the work, clinical evaluation of the cases, reviewing literature, Data collection and analysis, share in statistical analysis, write and revise the manuscript, share in preparation of the tables, share in preparation of the figures. EM discus the idea of the work, planning \& design the work, reviewing literature, Data collection and analysis, share in statistical analysis, write and revise the manuscript, share in preparation of the tables, share in preparation of the figures, revise figures, operate, interpretate \& reporting carotid duplex ultrasound study, interpretate \& reporting HRCT of the chest, publish the work in the journal. All authors read and approved the final manuscript.

\section{Funding}

This study had no funding from any resource.

\section{Availability of data and materials}

The datasets used and/or analyzed during the current study are available from the corresponding author on reasonable request.

\section{Competing interest}

The authors declare that they have no competing interests.

\section{Ethics approval and consent to participate}

This study was approved by the Research Ethics Committee of the Faculty of Medicine at Al-Azhar University (New Damietta), in Egypt, on 25 october 2016, reference number of approval: ADIMIRB 136/12. Informed consent obtained from study participants was written and assigned by participants. If the patient was less than 16 years old or unconscious at the time of the study, written informed consent for their participation was given by their parent or legal guardian.

\section{Consent for publication}

All patients included in this research gave written informed consent to publish the data contained within this study. If the patient was less than 16 years old, deceased, or unconscious when consent for publication was requested, written informed consent for the publication of this data was given by their parent or legal guardian.

\section{Author details}

Chest Diseases Department, Al-Azhar University, New Damietta, Egypt. ${ }^{2}$ Internal Medicine Department, Al-Azhar University, New Damietta, Egypt. ${ }^{3}$ Radiology Department, Al-Azhar University, Faculty of Medicine, New Damietta, Egypt.

Received: 28 August 2020 Accepted: 14 September 2020

Published online: 20 October 2020

\section{References}

1. GOLD. Global Initiative for Chronic Obstructive Lung Disease; global Strategy for the diagnosis, management, and prevention of chronic obstructive pulmonary disease; (2018)

2. Miller J, Edwards LD, Agusti A et al (2013) Comorbidity, systemic inflammation and outcomes in the ECLIPSE cohort. Respir Med 107(9):13761384

3. Rufino R (2006) Lapa e Silva JR. cellular and biochemical bases of chronic obstructive pulmonary disease. J Bras Pneumol 32(3):241-248
4. Junqueira VB, Barros SB, Chan SS, Rodrigues L, Giavarotti L, Abud RL et al (2004) Aging and oxidative stress. Mol Asp Med 25(1-2):5-16

5. Petta AD (2010) Pathogenesis of pulmonary emphysema. Cellular Molecular Events Einstein 8(2 Pt 1):248-251

6. Zakharchuk N, Nevzorova V, Brodskaya T, Gonchar E (2018) Chronic obstructive pulmonary disease and cardiovascular comorbidity. J Lung PulmRespir Res 5(1):00153

7. Barr RG, Mesia-Vela S, Austin JH et al (2007) Impaired flow-mediated dilation is associated with low pulmonary function and emphysema in ex-smokers: the emphysema and cancer action project (EMCAP) study. Am J RespirCrit Care Med 176:1200-1207

8. McAllister DA, Maclay JD, Mills NL et al (2007) Arterial stiffness is independently associated with emphysema severity in patients with chronic obstructive pulmonary disease. Am J Respir Crit Care Med 176:1208-1214

9. Mills NL, Miller JJ, Anand A et al (2008) Increased arterial stiffness in patients with chronic obstructive pulmonary disease: a mechanism for increased cardiovascular risk. Thorax 63:306-311

10. Eickhoff $P$, Valipour A, Kiss D et al (2008) Determinants of systemic vascular function in patients with stable chronic obstructive pulmonary disease. Am J RespirCrit Care Med 178:1211-1218

11. Iwamoto H, Yokoyama A, Kitahara Y et al (2009) Airflow limitation in smokers is associated with subclinical atherosclerosis. Am J RespirCrit Care Med 179:35-40

12. Kasahara $Y$, Tuder RM, Taraseviciene-Stewart $L$ et al (2000) Inhibition of VEGF receptors causes lung cell apoptosis and emphysema. J Clin Invest 106: $1311-1319$

13. Santos S, Peinado VI, Ramirez J et al (2003) Enhanced expression of vascular endothelial growth factor in pulmonary arteries of smokers and patients with moderate chronic obstructive pulmonary disease. Am J RespirCrit Care Med 167:1250-1256

14. Peinado VI, Barbera' JA, Abate P, et al. (1999) Inflammatory reaction in pulmonary muscular arteries of patients with mild chronic obstructive pulmonary disease. Am J RespirCrit Care Med 159:1605-1611

15. Matsuoka S, Yamashiro T, Diaz A, et. al. The relationship between small pulmonary vascular alteration and aortic atherosclerosis in chronic obstructive pulmonary disease: quantitative CT Analysis. Academic Radiology, (2011): Vol 18, No 1.

16. Ross R (1999) Atherosclerosis_an inflammatory disease. N Engl J Med 340: 115-126

17. Bonetti PO, Lerman LO, Lerman A (2003) Endothelial dysfunction: a marker of atherosclerotic risk. Arterioscler Thromb Vasc Biol 23:168-175

18. Anderson TJ, Uehata A, Gerhard MD et al (1995) Close relation of endothelial function in the human coronary and peripheral circulations. J Am CollCardiol 26:1235-1241

19. Neunteufl T, Katzenschlager R, Hassan A et al (1997) Systemic endothelial dysfunction is related to the extent and severity of coronary artery disease. Atherosclerosis 129:111-118

20. Al Qahtany FH, Al Shali HA, Bayamin AA et al (2018) Atherosclerosis: pathophysiology and management. Egyptian J Hospital Med 70:82-87

21. Sin DD, Man SF (2003) Why are patients with chronic obstructive pulmonary disease at increased risk of cardiovascular diseases? The potential role of systemic inflammation in chronic obstructive pulmonary disease. Circulation 107:1514e9

22. de Groot E, Hovingh GK, Wiegman A, Duriez P, Smit AJ, Fruchart JC et al (2004 Jun 15) Measurement of arterial wall thickness as a surrogate marker for atherosclerosis. Circulation 109:||l33e8

23. Yvette RBM, van Gestel W-JF et al (2010) Association of COPD with carotid wall intima-media thickness in vascular surgery patients. Respir Med 104 $712-716$

24. Lee HY, Oh BH (2010) Aging and arterial stiffness. Circulation 74:2257-2262

25. Galal-Eldin M, Ahmad E, Hafez M, Sobh E, Alrayes M (2015) Telomere length in chronic obstructive pulmonary disease. Egypt J Bronchol 9:20

26. Minamino T, Miyauchi H, Yoshida T, Ishida Y, Yoshida H, Komuro I (2002) Endothelial cell senescence in human atherosclerosis role of telomere in endothelial dysfunction. Circulation 105:1541-1544

27. Benetos A, Okuda K, Lajemi M, Kimura M, Thomas F, Skurnick J et al (2001) Telomere length as an indicator of biological aging the gender effect and relation with pulse pressure and pulse wave velocity. Hypertension 37:381-385

28. GOLD. Global Strategy of Diagnosis, Management and Prevention of COPD; 2014. Available from: URL: http:/ www.goldcopd.org.

29. Miller MR, Crapo R, Hankinson J, Brusasco V Burgos F, Casaburi R et al (2005) General considerations for lung function testing. EurRespir J 26:153-161 
30. Rankin G, Stokes M (1998) Reliability of assessment tools in rehabilitation: an illustration of appropriate statistical analyses. ClinRehabil 12:187-199

31. Maclay JD, Mcallister DA, Macnee W (2007) Cardiovascular risk in chronic obstructive pulmonary disease. Respirology 12:634-641

32. Fimognari FL, Scarlata S, Conte ME, Incalzi RA, Fimognari FL, Scarlata S et al (2008) Mechanisms of atherothrombosis in chronic obstructive pulmonary disease. Int J Chron Obstruct Pulmon Dis 3:89

33. Invernizzi G (2011) Persistence of systemic inflammation in COPD in spite of smoking cessation. MultidiscipRespir Med 6:210-211

34. Hafez MR, Sobh E, Abo-Elkheir OI, Sakr LK (2016) Atherosclerosis is associated comorbidity in patients with chronic obstructive pulmonary disease: ultrasound assessment of carotid intima media thickness. Eurasian J Pulmonol 18:165-171

35. Barr RG, Ahmed FS, Carr JJ, Hoffman EA, Jiang R, Kawut SM et al (2012) Subclinical atherosclerosis, airflow obstruction and emphysema: the MESA lung study. EurRespir J 39:846-854

36. Maclay JD, McAllister DA, Mills NL, Paterson FP, Ludlam CA, Drost EM et al (2009) Vascular dysfunction in chronic obstructive pulmonary disease. Am J RespirCrit Care Med 180:513-520

37. Brusasco V, Crapo R, Viegi G (2005) Series "ATS/ERS task force: standardization of lung function testing". EurRespir J 26:319-338

38. Touboul PJ, Hennerici MG, Meairs S, Adams H, Amarenco P, Bornstein N, et al. Mannheim carotid intima-media thickness consensus (2004e2006). An update on behalf of the Advisory Board of the 3rd and 4th Watching the Risk Symposium, $13^{\text {th }}$ and 15th European Stroke Conferences, Mannheim, Germany, 2004, and Brussels, Belgium, 2006. Cerebrovascular Dis 2007;23: $75 e 80$.

39. MonteiroJúnior FC, Mandarino NR, Santos EM, et. al. Correlation between serum 25-hydroxyvitamin D levels and carotid intima-media thickness in a Brazilian population descended from African slaves. Braz J Med Biol Res (2018); 51(4): e7185.

40. Sanders C, Bailey WC (1988) Detection of emphysema with computed tomography correlation with pulmonary function tests and chest radiography. Investig Radiol 23:262

41. Haruna A, Muro S, Nakano Y, Ohara T, Hoshino Y, Ogawa E et al (2010) CT scan findings of emphysema predict mortality in COPD. Chest 138(3):635-640

42. Doneen AL, Bale BF. Carotid intima-media thickness testing as an asymptomatic cardiovascular disease identifie and method for making therapeutic decisions. Postgraduate Medicine, Volume 125, Issue 2, March 2013,03:2645

43. Sabit R, Bolton CE, Edwards PH et al (2007) Arterial stiffness and osteoporosis in chronic obstructive pulmonary disease. Am J RespirCrit Care Med 175:1259-1265

44. Pauwels RA, Buist AS, Ma P, Jenkins CR, Hurd SS, GOLD Scientific Committee (2001) Global strategy for the diagnosis, management, and prevention of chronic obstructive pulmonary disease: National Heart, Lung, and Blood Institute and World Health Organization global initiative for chronic obstructive lung disease (GOLD): workshop summary. Respir Care 46(8):798-825

45. Alpaydin AO, Arslan IK, Serter S et al (2013) Metabolic syndrome and carotid intima-media thickness in chronic obstructive pulmonary disease. Multidiscip Respir Med 8:61

46. Kim SJ, Yoon DW, Lee EJ, et. al. Carotid atherosclerosis in patients with untreated chronic obstructive pulmonary disease. Int J Tuberc Lung Dis (2011);15(9):1265-1270.

47. Köseoğlu C, özgeKurmuş, GöktuğErtem A, et. al. Association between carotid intima-media thickness and presence of coronary artery disease in chronic obstructive pulmonary disease patients. Anatol J Cardiol 2016; 16: 601-607.

48. Savransky V, Nanayakkara A, Li J, Bevans S, Smith PL, Rodriguez A et al (2007) Chronic intermittent hypoxia induces atherosclerosis. Am J RespirCrit Care Med 175:1290-1297

49. Lattimore JD, Wilcox I, Nakhla S, Langenfeld M, Jessup W, Celermajer DS (2005) Repetitive hypoxia increases lipid loading in human macrophages-a potentially atherogenic effect. Atherosclerosis 179:255-259

50. Chen L, Einbinder E, Zhang Q, Hasday J, Balke CW, Scharf SM (2005) Oxidative stress and left ventricular function with chronic intermittent hypoxia in rats. Am J RespirCrit Care Med 172:915-920

51. Schroeder EB, Welch VL, Evans GW, et. al. Impaired lung function and subclinical atherosclerosis. The ARIC Study Atherosclerosis 2005; 180: 367-373.
52. Pike D, Kirby M, Lindenmaier TJ et al (2015) Pulmonary abnormalities and carotid atherosclerosis in ex-smokers without airflow limitation. COPD 12: 62-70

53. O'Brien KD, et. al. Vascular cell adhesion molecule-1 is expressed in human coronary atherosclerotic plaques. Implications for the mode of progression of advanced coronary atherosclerosis. J Clin Invest 1993;92: 945-951.

54. Dransfield MT, Huang F, Nath H, Singh SP, Bailey WC, Washko GR (2010) CT emphysema predicts thoracic aortic calcification in smokers with and without COPD. COPD 7(6):404-410

55. Chae EJ, Seo JB, Oh YM, Lee JS, Jung Y, Lee SD (2013) Severity of systemic calcified atherosclerosis is associated with airflow limitation and emphysema. J Comput Assist Tomogr 37(5):743-749

56. Pike D, Lindenmaier TJ, Sin DD, Parraga G (2014) Imaging evidence of the relationship between atherosclerosis and chronic obstructive pulmonary disease. Imaging Med 6(1):53-73

\section{Publisher's Note}

Springer Nature remains neutral with regard to jurisdictional claims in published maps and institutional affiliations.

\section{Submit your manuscript to a SpringerOpen ${ }^{\circ}$ journal and benefit from:}

- Convenient online submission

Rigorous peer review

- Open access: articles freely available online

- High visibility within the field

- Retaining the copyright to your article

Submit your next manuscript at $>$ springeropen.com 